\title{
Modeling ex-situ thermal impulse sensor responses to non-isothermal heating profiles
}

\author{
Benjamin R. Anderson ${ }^{1} \cdot$ Hergen Eilers ${ }^{1}$
}

Received: 28 August 2019 / Accepted: 8 November 2019 / Published online: 16 November 2019

(c) Springer Nature Switzerland AG 2019

\begin{abstract}
Ex-situ thermal impulse sensing based on irreversible phase transitions has been a developing field over the past two decades. Typically, these techniques determine thermal impulses assuming a perfect isothermal heating profile, which is not the case for real-life temperature profiles in extreme environments (e.g., structural fires, explosions, gas turbines). To better understand how real-world temperature profiles influence the sensors thermal impulse determinations, we perform phenomenological modeling of a thermal impulse sensor's response to non-isothermal heating with four-key profile characteristics: finite heating rate, nonzero cooling time constant, temperature spikes, and non-isothermal heating due to the finite size of sensors. We find that in all cases, these effects result in the corresponding equivalent isothermal temperature being lower than the peak temperature, while the equivalent isothermal duration is found to either be lengthened or shortened depending on the effect of interest. These results have important implications for the interpretation of thermal impulse calculations from a wide range of ex-situ thermal impulse sensors.
\end{abstract}

Keywords Phase transitions $\cdot$ Temperature sensing $\cdot$ Lanthanides $\cdot$ Zirconia $\cdot$ Yttria

\section{Introduction}

Over the past decade, we have developed and refined an ex-situ technique to measure the thermal impulse (i.e., temperature and duration) of nano/microparticles in extreme thermal environments (e.g., explosive fireballs and structural fires). This technique is based on irreversible phase transitions in lanthanide-doped inorganic oxide nanoparticles. These phase changes depend on the thermal impulse (TI) experienced by the particles and can be probed optically using photoluminescence spectroscopy of the dopant lanthanides. To date, we have tested a wide

Benjamin R. Anderson, branderson@wsu.edu | ${ }^{1}$ Applied Sciences Laboratory, Institute for Shock Physics, Washington State University, Spokane, WA 99210-1495, USA. 
variety of lanthanides and hosts for this purpose, including: precursors of both Eu: $\mathrm{ZrO}_{2}[1,2]$ and $\mathrm{Eu}: \mathrm{Y}_{2} \mathrm{O}_{3}[3,4]$, multicolored $\mathrm{Er}_{x} \mathrm{Yb}_{y} \mathrm{Zr}_{1-x-y} \mathrm{O}_{2} / \mathrm{Eu}_{0.02} \mathrm{Y}_{1.98} \mathrm{O}_{3}$ core/shell nanoparticles [5], $\mathrm{Tb}_{0.01} \mathrm{Zr}_{0.99} \mathrm{O}_{2}$ /(Precursor Eu $0.02 \mathrm{Y}_{1.98} \mathrm{O}_{3}$ ) core/ shell nanoparticles [6], and Eu:ZrO $/ \mathrm{Tb}_{2} \mathrm{Y}_{2} \mathrm{O}_{3}$ core/shell nanoparticles [7], $\mathrm{Cr}^{3+}: \mathrm{Al}_{2} \mathrm{O}_{3}{ }^{1}$ [8], p-Eu: $\mathrm{TiO}_{2}$ [9], p-Dy: $\mathrm{TiO}_{2}$, $p-D y: \mathrm{ZrO}_{2}$, and $\mathrm{p}-\mathrm{Dy}: \mathrm{Y}_{2} \mathrm{O}_{3}[10]$, and co-precipitated p-Eu:ZrO $\mathrm{Z}_{2} / \mathrm{p}-\mathrm{Dy}: \mathrm{Y}_{2} \mathrm{O}_{3}[11]$.

Based on these tests, we have determined a thermal impulse $(\mathrm{TI})$ sensor formulation consisting of a mixture of $\mathrm{p}-\mathrm{Dy}: \mathrm{Y}_{2} \mathrm{O}_{3}$ and $\mathrm{p}-\mathrm{Eu}: \mathrm{ZrO}_{2}[10-13]$. The use of two different precursor materials is necessary as each material provides a two-variable (temperature and duration) kinetic equation that cannot be solved without a second kinetic equation (i.e., solving for two variables requires two equations). In practice, these kinetic equations are determined by measuring different spectral properties (e.g., peak widths, intensity ratios) of samples heated in-lab to a wide range of temperatures and durations. These measurements result in calibration curves for both materials that are used in the field to correlate the measured spectral properties of recovered sensor particles to a specific thermal impulse.

While our ex-situ TI sensing technique relies on the spectral properties of $p-D y: \mathrm{Y}_{2} \mathrm{O}_{3}$ and $\mathrm{p}$-Eu:ZrO $\mathrm{Zr}_{2}$ for temperature sensing, there are other ex-situ techniques based on the same underlying principle (TI-dependent irreversible phase transitions) but utilize different materials and probe techniques. Some examples of these alternative techniques include: lifetime measurements of Eu:YSZ [14-22], irreversible changes to the resistance of nanowires [23], thermoluminescent microparticles [24-32], photoluminescence of $\mathrm{ZnAl}_{2} \mathrm{O}_{4}$ [33] and core-shell quantum dots [34], phospho-

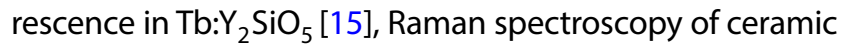
microparticles [35], Mossbauer parameters of a superconducting ceramic [36], modifications to thermally sensitive glass ceramics [37], photoluminescence and Raman spectroscopy of $\mathrm{ZnO}$ and $\mathrm{TiO}_{2}$ nanoparticles [38, 39], irreversible thermochromic behavior of Au/Ag nanorods [40] and polydiacetylene [41], and surface plasmon absorption [42-44].

In all of these techniques, the general procedure is to perform in-lab calibration using "isothermal" temperature profiles, which are then inverted to determine an equivalent isothermal TI for an unknown heating event. While this approach has proven to work well for measuring approximately isothermal heating profiles $[12,45]$, very few extreme environments have isothermal heating profiles. Instead, temperature profiles in extreme environments typically have a wide range of features, with some of the most common

\footnotetext{
${ }^{1}$ Note that while $\mathrm{Cr}^{3+}$ is not a lanthanide ion, it is still sensitive to changes in its local electric field, allowing it to be a probe of its local environment.
}

being finite heating rates, temperature spikes, and pseudoexponential cooling. Additionally, when considering the application of microparticle TI sensors in gaseous environments, size-dependent heating effects come into play making their temperature profiles non-isothermal, even if the gas temperature profile is isothermal.

Given the non-isothermal features of temperatures in extreme environments, it is unclear how to interpret the TI measured by these ex-situ techniques. Therefore, in order to better interpret the results obtained by these ex-situ techniques we perform modeling of temperature profiles containing different heating/cooling rates, temperature spikes, and size-dependent heating. For our modeling, we use a phenomenological model developed from experiments using our specific sensor cocktail [12]. While the specific quantitative results of this modeling are only valid for our sensors, the general qualitative trends identified are hypothesized to be similar for all the techniques described above. As a demonstration of these principles, we apply this modeling to a generalized TI sensor material model and show how different material parameters influence the quantitative performance, while the qualitative trends remain the same.

\section{Models}

\subsection{Idealized model of irreversible phase transitions}

The general theory of phase kinetics has been widely studied over the past century $[46,47,47-51,51-58]$. Based on this research, we can model almost any irreversible phase transition using a generalized differential equation given by [46-51]:

$\frac{\mathrm{d} \alpha}{\mathrm{d} t}=h(T) f(\alpha)$,

where $\alpha$ is the degree of conversion of the phase transition, $h(T)$ is an Arrhenius function, and $f(\alpha)$ is a function dependent on the transformation mechanism. Note that Eq. 1 is for a single phase, with multiple phase transitions requiring the use of coupled differential equations. In general, $h(T)$ is given by

$h(T)=A \exp \left[-\frac{E}{k T(t)}\right]$,

where $A$ is a rate constant, $E$ is the transformation energy barrier, and $k$ is Boltzmann's constant. In the case of $f(\alpha)$, the precise form depends on the phase transformation mechanism with a general expression for it being given by [46]: 
$f(\alpha)=\alpha^{m}(1-\alpha)^{n}[-\ln (1-\alpha)]^{p}$

where $m, n$, and $p$ depend on the reaction mechanism [46, 47, 51-58]. Substituting Eqs. 2 and 3 into Eq. 1, we find the whole kinetic equation to be:

$\frac{\mathrm{d} \alpha}{\mathrm{d} t}=A \exp \left[-\frac{E}{k T(t)}\right] \alpha^{m}(1-\alpha)^{n}[-\ln (1-\alpha)]^{p}$.

Rearranging Eq. 4 and integrating, we obtain a general solution of:

$$
\begin{gathered}
\int_{\alpha_{0}}^{\alpha} \frac{\mathrm{d} \alpha^{\prime}}{\alpha^{\prime m}\left(1-\alpha^{\prime}\right)^{n}\left[-\ln \left(1-\alpha^{\prime}\right)\right]^{p}} \\
\quad=A \int_{t_{0}}^{t} \exp \left[-\frac{E}{k T\left(t^{\prime}\right)}\right] \mathrm{d} t^{\prime} .
\end{gathered}
$$

Further simplification of the general case is not possible as both integrals depend on the specific functional forms, with their solutions typically requiring numerical integration.

While general simplification is not possible, we can consider an example of a common phase transition in inorganic oxides (nucleation and grain growth), which has exponent values of $m=0, n=1, p=0$ [46]. Assuming that the material begins completely in the initial phase, i.e., $\alpha_{0}=0$, Eq. 5 can be integrated to give the degree of conversion as a function of time to be:

$\alpha(t)=1-\exp \left\{-A \int_{t_{0}}^{t} \exp \left[-\frac{E}{k T\left(t^{\prime}\right)}\right] \mathrm{d} t^{\prime}\right\}$.

The integral in Eq. 6 typically requires numerical integration with only a few simple temperature profiles (e.g., isotherm, linear ramp) having analytical solutions. In the case of an isothermal temperature profile, we can write the solution as:

$$
\begin{aligned}
\alpha(t) & =1-\exp \left\{-A \exp \left[-\frac{E}{k T_{\text {iso }}}\right]\left(t-t_{0}\right)\right\}, \\
& =1-\exp \left\{-A \exp \left[-\frac{E}{k T_{\text {iso }}}\right] \Delta t\right\},
\end{aligned}
$$

where $T_{\text {iso }}$ is the isothermal temperature and $\Delta t=t-t_{0}$ is the duration of the isotherm.

\subsection{Phenomenological model}

Based on our experimental observation of how the intensity ratios of our $\mathrm{TI}$ sensors change with temperature and duration [10,12], we have determined that the spectral ratios can be modeled using a phenomenological model, where the ratios as a function of the thermal impulse $\Theta$ are given by:
Table 1 Material parameters used in simulations

\begin{tabular}{lll}
\hline & Material 1 & Material 2 \\
\hline$R_{0}$ & 1 & 1 \\
$R_{A}$ & -1 & -1 \\
$\mathrm{~A}_{i}\left(\mathrm{~ms}^{-1}\right)$ & 0.1 & 0.12 \\
$T_{i}(\mathrm{~K})$ & 750 & 950 \\
$\beta$ & 10 & 10 \\
\hline
\end{tabular}

$R(\Theta)=R_{0}+R_{A} e^{-\Theta}$

where $R_{0}$ is the initial ratio, $R_{A}$ is an amplitude parameter, and the thermal impulse is defined as:

$\Theta=A \int_{0}^{t} \exp \left[-\left(\frac{T_{c}}{T\left(t^{\prime}\right)}\right)^{\beta}\right] \mathrm{d} t^{\prime}$,

with $A$ being a rate constant, $T_{c}$ is a characteristic temperature, $\beta$ is a stretch exponent, and $T(t)$ is the time-dependent heating profile.

For our TI sensors, we use two different materials with unique kinetic parameters which results in two spectral ratios given by:

$R_{1}=R_{0,1}$

$$
+R_{A, 1} \exp \left\{-A_{1} \int_{0}^{t_{1}} \exp \left[-\left(\frac{T_{1}}{T\left(t^{\prime}\right)}\right)^{\beta_{1}}\right] \mathrm{d} t^{\prime}\right\},
$$

$$
\begin{aligned}
R_{2}= & R_{0,2} \\
& +R_{A, 2} \exp \left\{-A_{2} \int_{0}^{t_{1}} \exp \left[-\left(\frac{T_{2}}{T\left(t^{\prime}\right)}\right)^{\beta_{2}}\right] \mathrm{d} t^{\prime}\right\} .
\end{aligned}
$$

These two ratios can then be measured to probe the temperature profile experienced by our sensors. While we would ideally be able to invert these equations to get the actual temperature profile from measuring the two ratios, this is generally unfeasible.

However, while we cannot obtain the precise temperature profile by only measuring the two ratios, we can instead use the two ratios to determine an equivalent isothermal temperature profile that has the same thermal impulse as the actual heating event. To perform this calculation, we begin by writing Eqs. 10 and 11 for an isothermal temperature profile,

$R_{1}=R_{0,1}+R_{A, 1} \exp \left\{-A_{1} \exp \left[-\left(\frac{T_{1}}{T_{\text {iso }}}\right)^{\beta_{1}}\right] \Delta t\right\}$, 
$R_{2}=R_{0,2}+R_{A, 2} \exp \left\{-A_{2} \exp \left[-\left(\frac{T_{2}}{T_{\text {iso }}}\right)^{\beta_{2}}\right] \Delta t\right\}$.

where $T_{\text {iso }}$ is the equivalent isothermal temperature and $\Delta t$ is the equivalent isothermal duration. In general, Eqs. 12 and 13 require numerical solutions to solve for both $T_{\text {iso }}$ and $\Delta t$. However, in the case of $\beta_{1}=\beta_{2}=\beta$ we can write an analytical solution for both $T_{\text {iso }}$ and $\Delta t$ :

$T_{\text {iso }}=\left(T_{2}^{\beta}-T_{1}^{\beta}\right) \ln \left[\frac{A_{2} \ln \left(1-R_{1}\right)}{A_{1} \ln \left(1-R_{2}\right)}\right]^{-1 / \beta}$,

$\Delta t=\frac{-\ln \left(1-R_{1}\right)}{A_{1}} \exp \left\{\left(\frac{T_{1}}{T_{\text {iso }}}\right)^{\beta}\right\}$,

To model the performance of our TI sensors in response to non-isothermal heating events, we first calculate both materials' ratios using Eqs. 10 and 11, with the simulated material parameters tabulated in Table 1 . Once these ratios are calculated, we plug them into Eqs. 14 and 15 to determine the equivalent isothermal temperature and duration for the heating event.

\subsection{Heat transfer model}

The phenomenological model described above allows us to model the ratios for any temperature profile experienced by the sensors. However, it is only one of the two models we need in order to simulate the influence of particle size on particles exposed to a hot gas flow (e.g., an explosion). To model the influence of particle size, we utilize a lumped capacitance heat transfer model, in which we only consider convective heat flow into the particles and assume that heat transfer within the particles is rapid enough to be negligible. This assumption is appropriate for situations where the Biot number is less than 1 [59], which we will demonstrate to be true after deriving the relevant equations.

In the case of the lumped capacitance approximation, we write the total heat flux into a sensor particle as

$\dot{Q}_{\text {Tot }}=\dot{Q}_{\text {Conv }}+\dot{Q}_{\text {Rad }}$

where $\dot{Q}_{\text {Tot }}$ is the total absorbed heat flux, $\dot{Q}_{\text {Conv }}$ is the heat due to convection, and $Q_{\text {Rad }}$ is the heat flux due to thermal radiation. Using well-known relationships for these values, we determine a master differential equation,

$\rho C_{p} V \frac{\partial T}{\partial t}=h A\left(T_{g}-T\right)+\epsilon \sigma A\left(T_{g}^{4}-T^{4}\right)$,

where $\rho$ is the particle's density, $C_{p}$ is the particle's heat capacity, $V$ is the particle's volume, $A$ is the particle's surface area, $T_{g}$ is the gas temperature, and $h$ is the heat
Table 2 Parameters used in heat transfer calculations

\begin{tabular}{lll}
\hline Parameter & Value & \\
\hline $\mathrm{u}$ & 10 & $\mathrm{~m} \mathrm{~s}^{-1}$ \\
$\mu_{0}$ & 1.846 & $10^{-5} \mathrm{~N} \mathrm{~s} \mathrm{~m}^{-2}$ \\
$\mu_{\infty}$ & 4.153 & $10^{-5} \mathrm{~N} \mathrm{~s} \mathrm{~m}^{-2}$ \\
$v$ & 1.176 & $10^{-4} \mathrm{~m}^{2} / \mathrm{s}$ \\
$k_{g}$ & 0.06754 & $\mathrm{~W} \mathrm{~m}^{-1} \mathrm{~K}^{-1}$ \\
$S$ & 110 & $\mathrm{~K}$ \\
$\operatorname{Pr}$ & 0.702 & \\
\hline
\end{tabular}

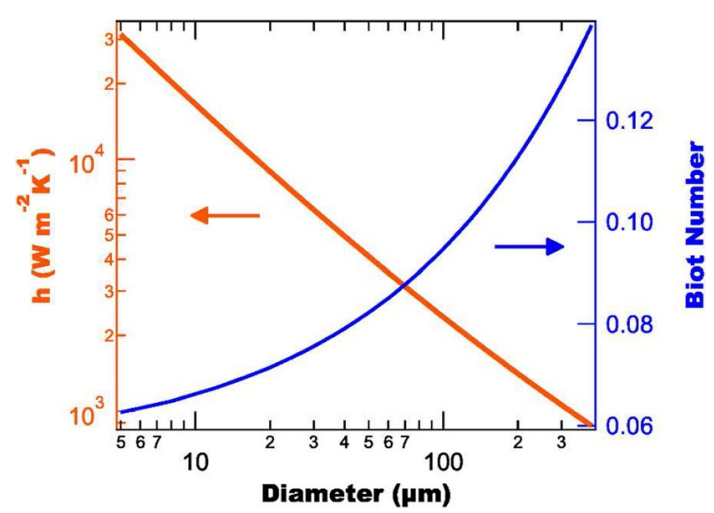

Fig. 1 Example convective heat transfer coefficient and Biot number as a function of particle diameter for a gas temperature of $1000 \mathrm{~K}$

transfer coefficient. Rearranging Eq. 17 and substituting in the formula for a sphere's volume and surface area, we obtain the following differential equation:

$\frac{\partial T}{\partial t}=\frac{6 h}{\rho C_{p} D}\left(T_{g}-T\right)+\frac{6 \epsilon \sigma}{\rho C_{p} D}\left(T_{g}^{4}-T^{4}\right)$.

While the majority of parameters in Eq. 18 are constants that can be looked up in reference books, the heat transfer coefficient is found to depend on both the gas temperature and particle size as:

$h\left(T_{g}, D\right)=\frac{k_{g} N u\left(T_{g}, D\right)}{D}$,

where $k_{g}$ is the thermal conductivity of the gas and $N u\left(T_{g}, D\right)$ is the Nusselt number.

For a sphere in forced convection, the Nusselt number is given by

$\mathrm{Nu}=2+\left(0.4 \operatorname{Re}^{1 / 2}+0.06 \operatorname{Re}^{2 / 3}\right) \operatorname{Pr}^{0.4}\left(\frac{\mu_{\infty}}{\mu(T)}\right)^{1 / 4}$,

where Pr is the Prandtl number, $\mu_{\infty}$ is the static viscosity at $T_{g^{\prime}}$ Re is the Reynolds number, which is 


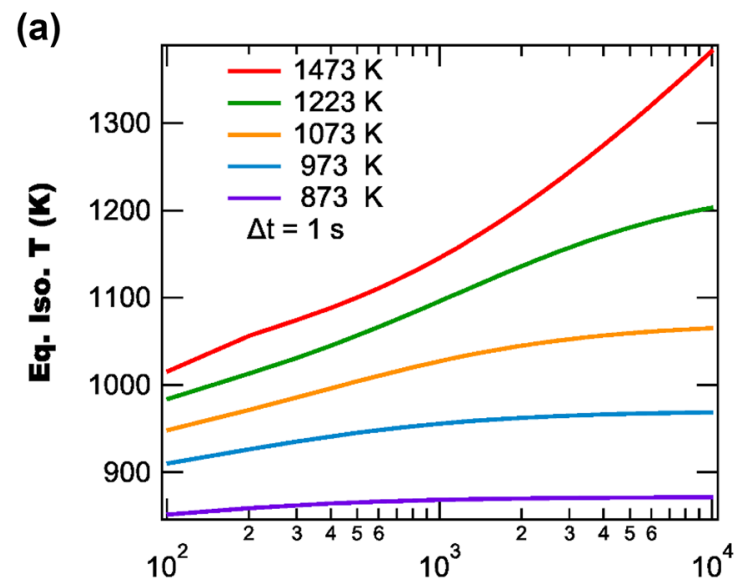

Heating Rate (K/s)

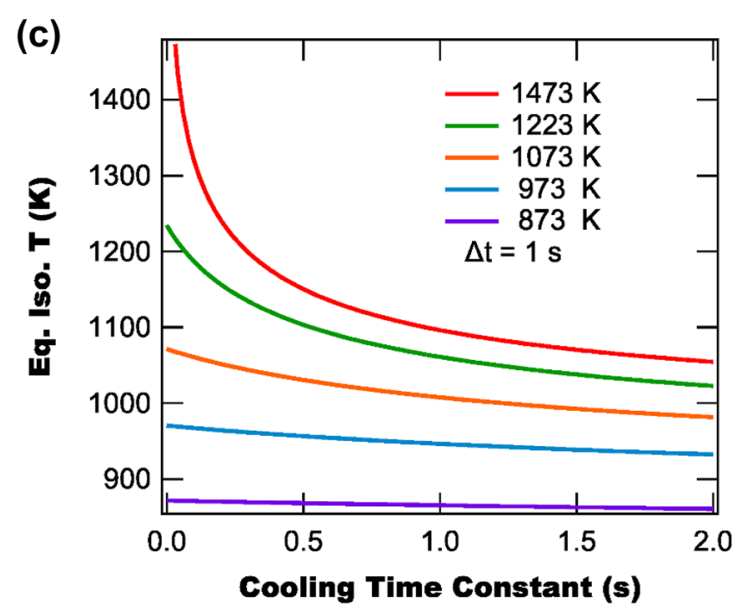

(b)

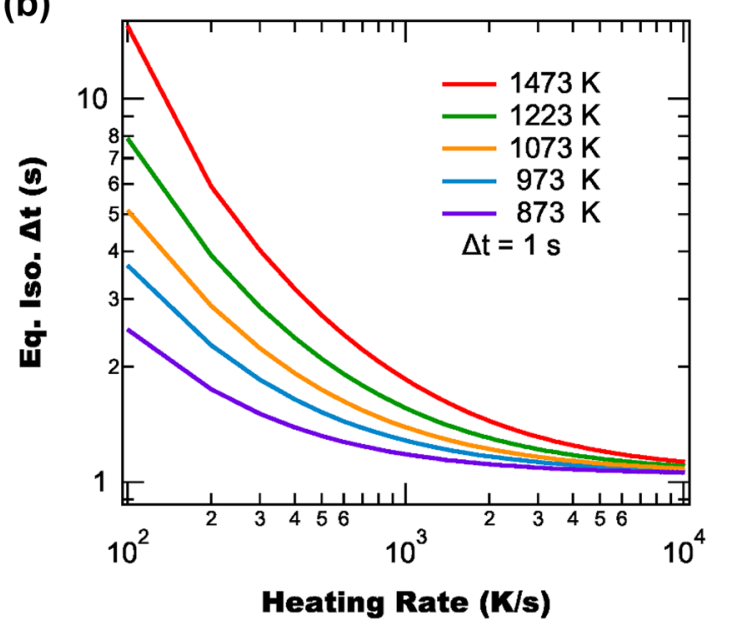

(d)

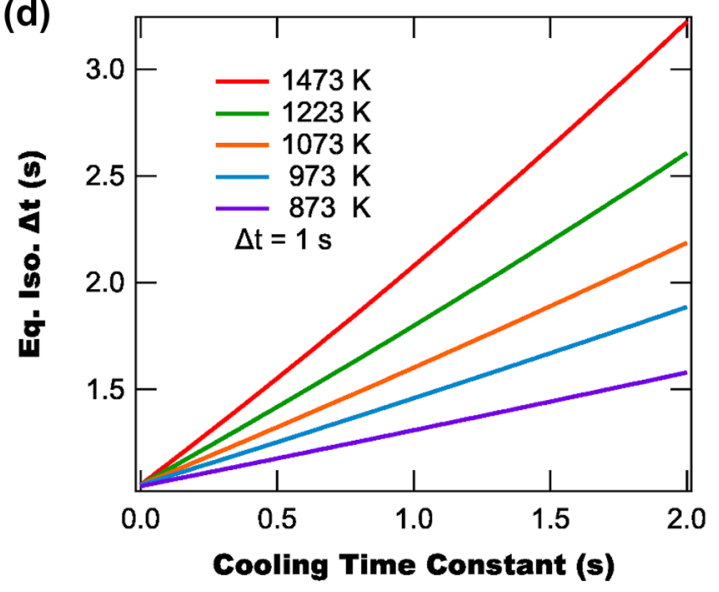

Fig. 2 Equivalent isothermal temperature $(\mathbf{a}, \mathbf{c})$ and duration $(\mathbf{b}, \mathbf{d})$ as a function of heating rate and cooling time constant for different isothermal temperatures and a duration of $1 \mathrm{~s}$

$\operatorname{Re}=\frac{u D}{v}$,

with $u$ being the gas slip velocity, $v$ the kinetic viscosity of the gas, and $\mu(T)$ is the temperature dependent viscosity, which follows Sutherland's law:

$\mu(T)=\mu_{0}\left(\frac{T}{T_{0}}\right)^{3 / 2} \frac{T_{0}+S}{T+S}$

where $\mu_{0}$ is the static viscosity at $T_{0}$ and $S$ is a constant. Combining Eqs. 19-22 and simplifying, we write the sizedependent heat transfer coefficient as

$$
\begin{aligned}
h= & \frac{k_{g}}{D}\left\{2+\left[0.4\left(\frac{u D}{v}\right)^{1 / 2}\right.\right. \\
& \left.\left.+0.06\left(\frac{u D}{v}\right)^{2 / 3}\right] \operatorname{Pr}^{0.4}\left(\frac{\mu_{\infty}}{\mu(T)}\right)^{1 / 4}\right\} .
\end{aligned}
$$

To demonstrate the size-dependent heat transfer coefficient, we use the material parameters of air at $1000 \mathrm{~K}$ (tabulated in Table 2) and plot $h$ for diameters ranging from 5 $\mu \mathrm{m}$ to $200 \mu \mathrm{m}$ in Fig. 1. From Fig. 1, we find that the heat transfer coefficient starts near $32 \mathrm{~kW} / \mathrm{m}^{2} \mathrm{~K}$ and decreases to around $1 \mathrm{~kW} / \mathrm{m}^{2} \mathrm{~K}$ for a diameter of $200 \mu \mathrm{m}$. Finally, to check the validity of the lumped capacitance model we plot the Biot number $(B i=h D / k)$ in Fig. 1, where we have used $\mathrm{ZrO}_{2}$ 's heat conductivity $k$. From Fig. 1, we find that the Biot number is less than 1 for all diameters considered, which supports the use of the lumped capacitance model. 


\section{Results}

\subsection{Effect of heating and cooling rates}

The first non-isothermal temperature profiles we model are ones consisting of a linear temperature ramp to an isothermal temperature held for a fixed duration $(1 \mathrm{~s}$ for the results shown in this section), followed by exponential cooling. This temperature profile is an approximation of the heating curves experienced during our calibration measurements [12]. The two parameters in this temperature profile that will cause our equivalent isotherm to deviate from the actual isothermal portion are the heating rate and the cooling time constant. To better understand the influence of each, we performed modeling in which we allowed one parameter to vary, while assuming the other parameter corresponded to a perfect isotherm (e.g., infinite heating rate when considering the effect of cooling time constant). Figure 2 shows the resulting equivalent isothermal temperatures and durations as a function of heating rate and cooling time constant from this modeling.

From Fig. $2 a$ and $b$, we find that at low heating rates the equivalent isothermal temperature is significantly lower than the actual isothermal temperature, while the duration is significantly longer than the actual isothermal duration. This result is intuitive as slow heating rates result in the sensors experiencing lower temperatures for the majority of the total duration, which minimizes the contribution of the isothermal portion. Note that this effect scales with the actual isothermal temperature due to the time required to ramp to a given temperature (i.e., at lower temperatures less time is required to reach the isothermal portion of the temperature profile).

Having considered the influence of heating rate, we next consider the effect of the cooling time constant, whose equivalent isothermal temperature and duration are shown in Figs. $2 c$ and d, respectively. Similar to the heating rates above, we find that the faster the sensors cool, the more closely the equivalent and actual isotherms match. Figure $2 \mathrm{c}$ shows that the equivalent isothermal temperature follows an inverse function with the time constant, while the equivalent isothermal duration scales linearly with the time constant (see Fig. 2d), with the slope depending on the isothermal temperature. Once again at higher isothermal temperatures, these effects are more pronounced.

Based on these results, we can conclude that both the heating and cooling rates can have a significant impact on the calculated equivalent thermal impulse, with slow heating and/or cooling being the dominate component of the thermal impulse. This observation is especially important when considering our TI sensors' calibration, as the

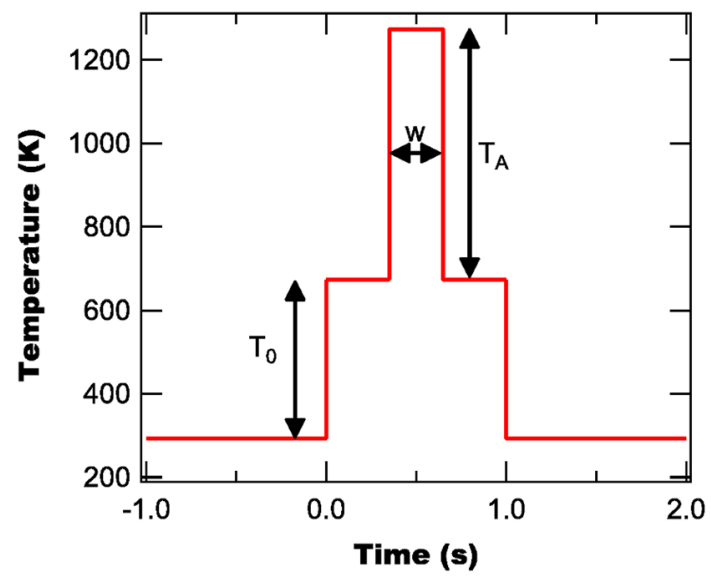

Fig. 3 Example temperature profile consisting of a low-temperature isotherm with an additional high-temperature square peak

model temperature profile approximates the calibration temperature profile. If our calibration is performed using either slow heating and/or cooling, the heating/cooling period(s) will dominate the phase transitions resulting in our calibration being skewed. This skew will cause the incorrect results when we apply our sensors in the field. To avoid having an incorrect calibration due to heating and cooling effects, we need to heat and cool the sensors sufficiently fast. From Fig. 2, we determine that the ideal heating rate will be over $10,000 \mathrm{~K} / \mathrm{s}$ and the ideal cooling time constant is $<100 \mathrm{~ms}$.

\subsection{Effect of a temperature pulse}

In the above section, we considered a temperature profile that approximates the temperature profiles used during calibration. Next we consider an idealized model of a likely temperature profile experienced in our proposed applications. This profile consists of a long-duration low-temperature background with short high-temperature peaks $[60,61]$. These peaks arise in the context of explosions as the particles flow through a heterogeneous fireball that contain both hot and cold spots [61], while in the context of structural fires we find that temperature spikes occur due to flashovers [60].

To model the effect of a temperature spike on our equivalent isothermal calculations, we compute Eqs. 10 and 11 for a temperature profile consisting of a $1 \mathrm{~s}$ duration $673 \mathrm{~K}$ isotherm, to which we add a square temperature spike of amplitude $T_{A}$ and width $w$, as shown in Fig. 3. Once we compute the temperature profiles' two ratios, we then determine the equivalent isotherms. Figure $4 a$ displays the equivalent isothermal temperature and Fig. $4 \mathrm{~b}$ displays the equivalent isothermal duration as a function of the peak width and peak temperature $\left(T_{P}=T_{0}+T_{A}\right)$. 

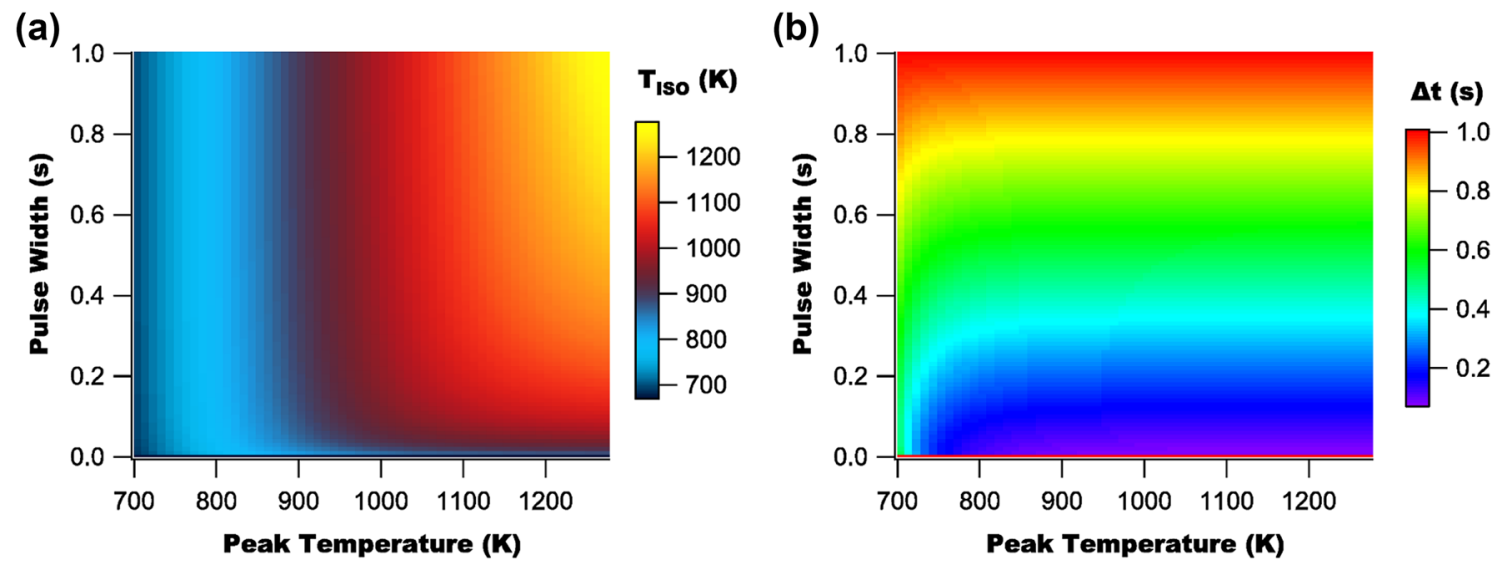

Fig. 4 Calculated isothermal temperature (a) and duration (b) as a function of pulse width and temperature
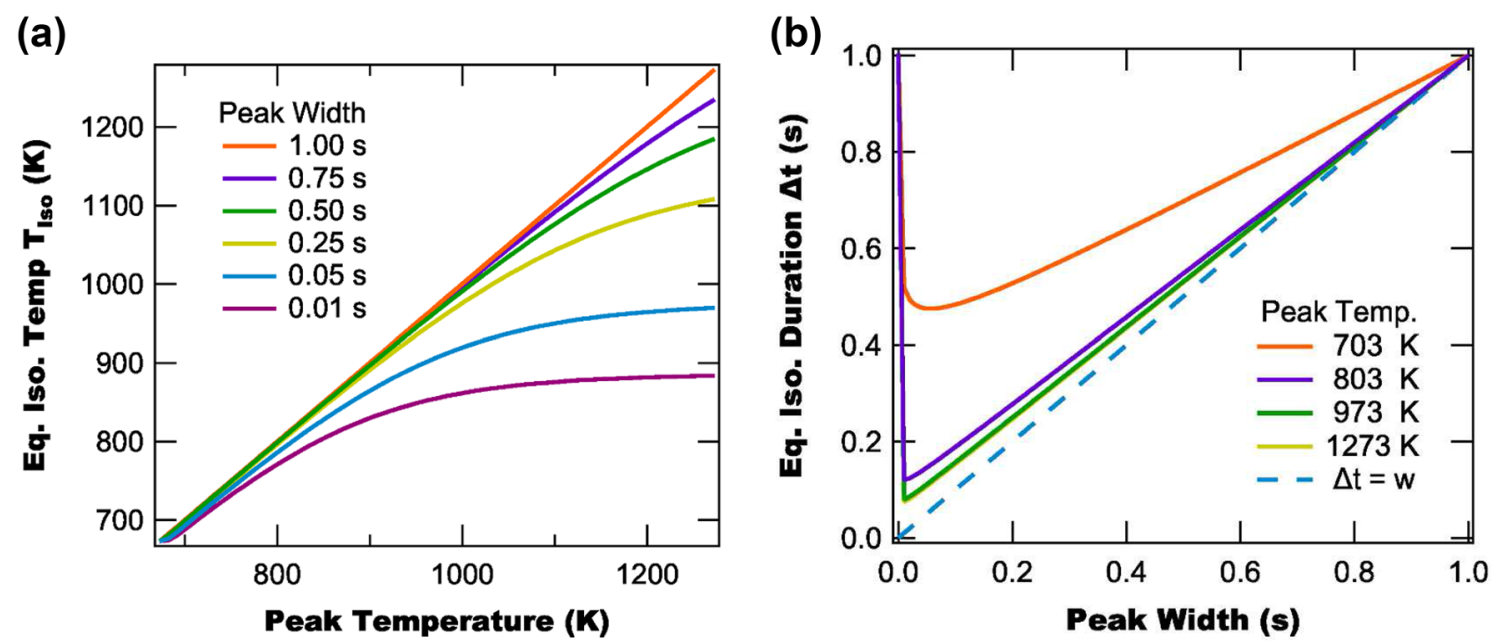

Fig. 5 Calculated isothermal temperature (a) and duration (b) as a function of pulse width and temperature

From Fig. 4, we find that in the two extreme peak width cases ( $w=0$ and $w=1 \mathrm{~s}$ ), the results are as expected, with the isothermal temperature and duration either being $673 \mathrm{~K}$ and $1 \mathrm{~s}$ (for $w=0$ ) or the full temperature $\left(T_{p}\right)$ for $1 \mathrm{~s}$ $(w=1 \mathrm{~s})$. In the intermediate cases $\left(T_{A}>0\right.$ and $\left.0<w<1\right)$, we find from Fig. 4 that the inclusion of the temperature peak results in the equivalent isothermal temperature being $T_{0}<T_{\text {iso }}<T_{0}+T_{A}$, and the duration being greater than the pulse width $(\Delta t>w)$. This means that the equivalent isothermal temperature will always be less than the peak temperature and the equivalent duration will be greater than the peak width.

To better understand these results, we plot specific one-dimensional curves from Fig. 4 in Fig. 5, with Fig. 5a showing the influence of the peak temperature on the equivalent isothermal temperature and Fig. $5 \mathrm{~b}$ showing the influence of the peak width on the equivalent isothermal duration. From Fig. 5a, we find that for a peak duration of $1 \mathrm{~s}$, the peak temperature and equivalent isothermal temperature match as expected. However, as the peak duration shortens the equivalent value diverges toward lower temperature values, with the difference being significant at higher temperatures. We also find that the shorter the duration, the larger this deviation between the peak value and equivalent isothermal temperature becomes, with the shortest peak width (10 ms) having a significantly lower equivalent isothermal temperature than the peak value. These results are consistent with previous observation of particle sensors recovered from an explosion producing lower equivalent isothermal temperatures than predicted by modeling [61, 62].

In the case of the peak width, we find from Fig. $5 b$ that as $w$ increases the equivalent isothermal duration quickly drops to slightly above the peak duration. This implies that for temperature profiles containing a temperature 


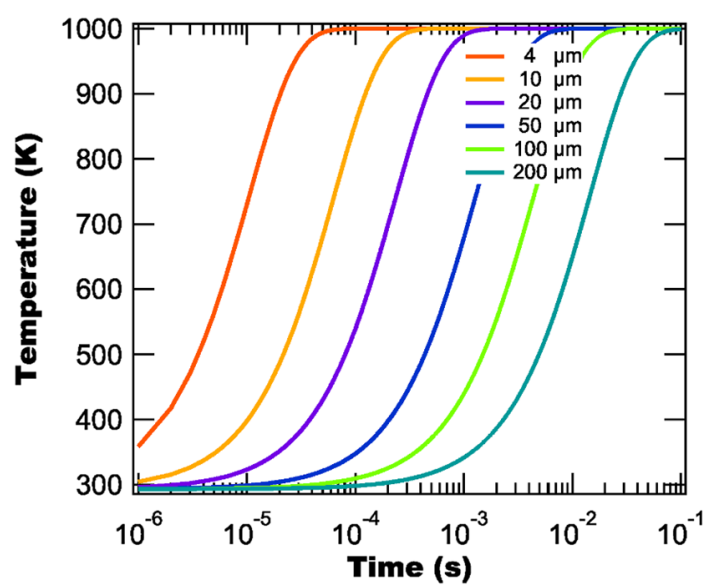

Fig. 6 Temperature profiles of different diameter particles exposed to a $1000 \mathrm{~K}$ environment

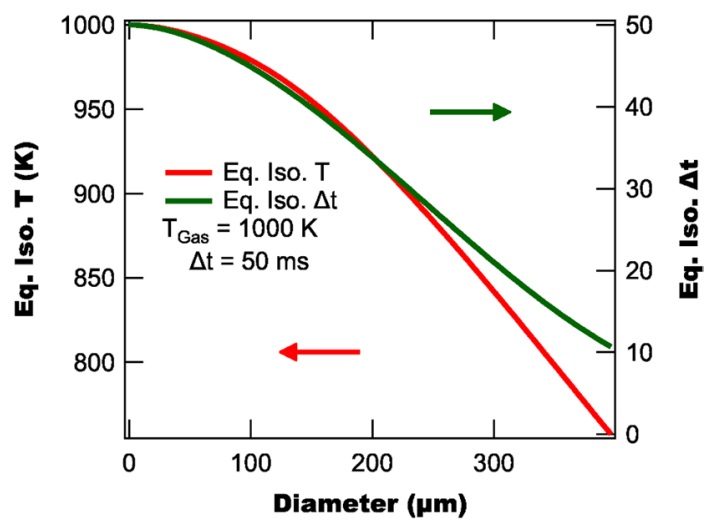

Fig. 7 Example equivalent isothermal temperature and duration as a function of sensor diameter for an exposure time of $50 \mathrm{~ms}$ peak, our equivalent isotherm will have a duration slightly greater than the peak width (but less than the full "isothermal" duration) with the calculated duration approaching the peak width with increase in peak temperature. Interestingly, from Fig. $5 \mathrm{~b}$ we also find that for temperatures above $\approx 850 \mathrm{~K}$ the calculated duration is the same regardless of the temperature. This result is due to the ratios temperature dependence being a stretched Arrhenius function (Eq. 9) which essentially becomes constant above a certain temperature.

Combining the results discussed above, we determine that in the case of a temperature spike occurring on top of a longer duration isotherm, the equivalent isothermal temperature will be less than the peak temperature and the equivalent duration will be greater than the peak width but less than $\Delta t$.

\subsection{Particle size effects}

Having considered the effect of several idealized temperature profiles in the above sections, we now turn to considering a non-isothermal temperature profile resulting from real-world limitations, namely the finite size of our TI sensor particles. This nonzero size results in the temperature experienced by the sensors being limited by heat transfer into the particles, which depends on the particle size (see Eq. 23). Using the heat transfer model described above, we simulate heat transfer from a hot gas into the particles assuming a fixed exposure time and gas temperature, with Fig. 6 showing temperature profiles for different particle diameters as a function of time for particles exposed to a $1000 \mathrm{~K}$ gas for $100 \mathrm{~ms}$. From Fig. 6, we find that the smallest diameter particle rapidly approaches the

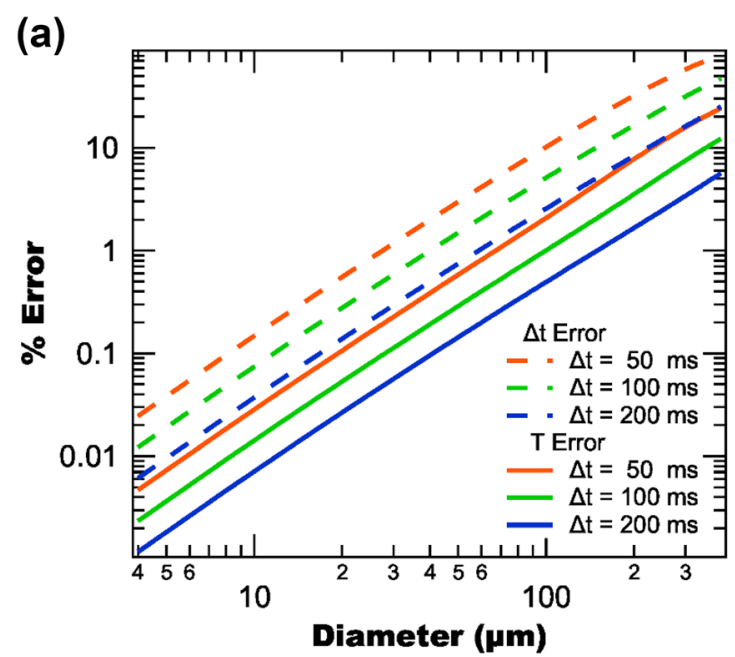

(b)

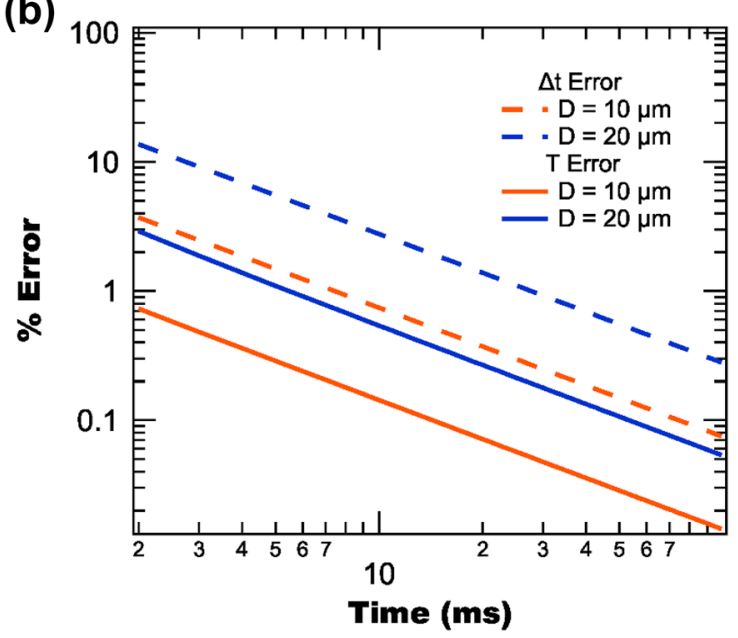

Fig. 8 Percent error of equivalent isothermal temperature (solid lines) and duration (dashed lines) as a function of particle diameter (a) and exposure time (b) 
gas temperature within the first $50 \mu \mathrm{s}$ of exposure, while the largest diameter particle $(200 \mu \mathrm{m})$ takes almost $100 \mathrm{~ms}$ to reach the gas temperature.

This difference in rise times results in significant variations in the equivalent isothermal temperatures and durations determined by each particle size. To demonstrate this effect, we calculate the equivalent isothermal temperature and duration for different sized particles exposed to a $1000 \mathrm{~K}$ gas for $50 \mathrm{~ms}$, with the resulting equivalent temperatures and durations shown in Fig. 7. From Fig. 7, we find that as the particle size increases both the equivalent temperature and duration decreases. Practically, this means that finite-sized TI sensors will always measure smaller equivalent isothermal temperatures and durations than the actual isothermal gas temperature and duration.

To quantify our equivalent isotherm's error compared to the true isothermal values, we model the influence of diameter for several different durations and then compute the percent error (i.e., \% Error = Equivalent value/actual value $\times 100$ ). Figure 8 a shows the percent error of both the equivalent isothermal temperature and duration as a function of diameter for different particle exposure times, while Fig. $8 \mathrm{~b}$ displays the same quantities as a function of exposure time for two different diameters. From Fig. 8a and $b$, we find that the percent error depends nonlinearly on both the particle diameter and exposure time, with the error increasing with diameter, while the reverse is true for exposure time, in which longer exposure results in smaller errors. Performing fits to the different curves we develop a model equation for the percent error:

$\mathrm{PE}=A\left(1-\exp \left\{-b \frac{D^{2}}{\Delta t^{2}}\right\}\right)$,

where $A$ and $b$ are adjustable parameters that depend on the various thermal properties of both the gas and particles.

Given the percent error's nonlinear dependence on diameter, it becomes clear that it is imperative to utilize small particles, with a narrow size distribution. While we would ideally make the smallest particles possible (to minimize the error), in practice there are other considerations that come into play limiting the size, namely government safety regulations on particulate sizes and the increasing difficulty of recovering particles with decrease in size. If the particles become too small, it becomes significantly harder to collect the particles and analyze them after the event as we probe the sensors using photoluminescence, whose intensity depends on the particle size.

\subsection{Applying modeling to other TI sensors}

In the above sections, we presented the results of modeling the response of our TI sensors to non-isothermal heating events. While we specifically used our sensors TI response for modeling, these results should be qualitatively the same for all $\mathrm{TI}$ sensors based on irreversible phase transitions, with the quantitative values differing depending on specific sensors TI response. At this point, it would be ideal to present tuning of our model to a different TI sensor to compare the results. Unfortunately, such a detailed analysis is not possible as information on other sensors TI response curves is limited. Many of the studies on $\mathrm{TI}$ sensors in the literature have focused on the temperature-sensing aspect and have failed to report on the sensors time dependence [17-20, 22, 24, 29, 63-65]. Therefore, due to this lack of detail, we cannot specifically apply our modeling to these sensors.

However, while we cannot model a specific example from the literature, we can demonstrate the effect of varying the material parameters on the sensor performance, which is equivalent to "tuning" the model to a new sensor formulation. For this demonstration, we assume the same functional form of the sensor response (Eqs. 10 and 11) but with new parameter values (e.g., $A_{i}, T_{i}$, and $\beta$ ). Note that while these equations have not previously been used with other TI sensor compositions, they most likely would be able to model those sensors TI responses as well. This is due to the vast majority of ex-situ TI sensors reported in the literature having response curves that are Arrheniuslike in temperature and exponential in time. $[15,66]$

For our demonstration, we consider two different nonisothermal temperature profiles consisting of a linear ramp followed by a $1 \mathrm{~s}$ isotherm, with instantaneous cooling. One profile has an isothermal temperature of $800 \mathrm{~K}$, while the other has an isothermal temperature of $1273 \mathrm{~K}$. These two profiles represent two distinct cases: 1 ) an isothermal temperature in between the two sensors characteristic temperatures and 2) an isothermal temperature above both sensors characteristic temperatures. For both these cases, we model the $\mathrm{TI}$ sensor response while varying one of the material parameters and holding the other parameters constant. Figure 9 shows the resulting equivalent isothermal temperatures and durations as a function of each parameter for both the $800 \mathrm{~K}$ and $1273 \mathrm{~K}$ isotherm. Note that we do not show a figure for the amplitudes as the sensor responses are found to be independent of the amplitude. This invariance is due to the $\ln \left(1-R_{i}\right)$ term in Eq. 14 being proportional to $A_{i}$, which leads to Eq. 14 being independent of both $A_{i}$ 's.

From Fig. 9, we observe that the qualitative results (underestimating $T_{\text {iso }}$ and overestimating $\Delta t$ ) are independent of the parameters used, while the quantitative 


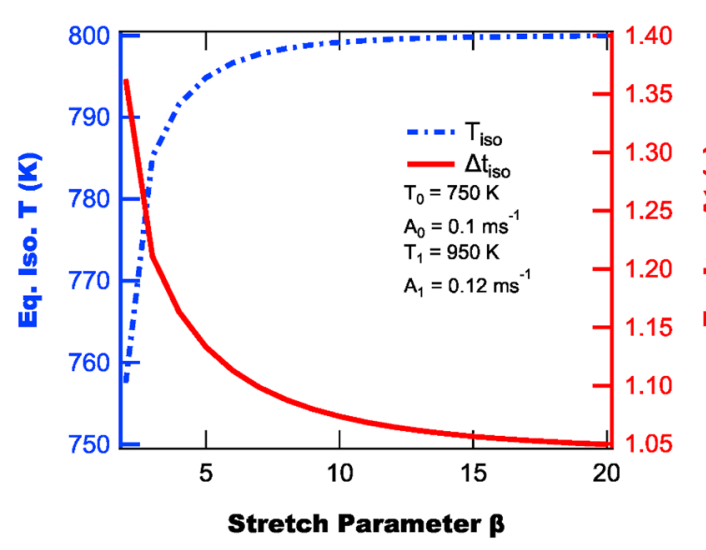

(a)

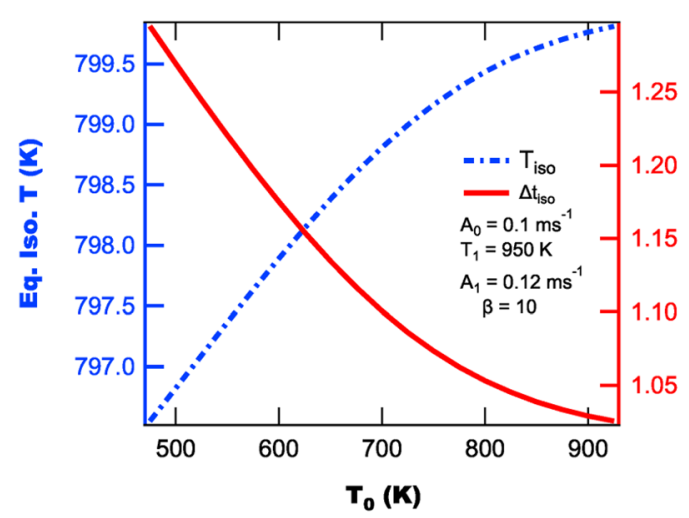

(c)

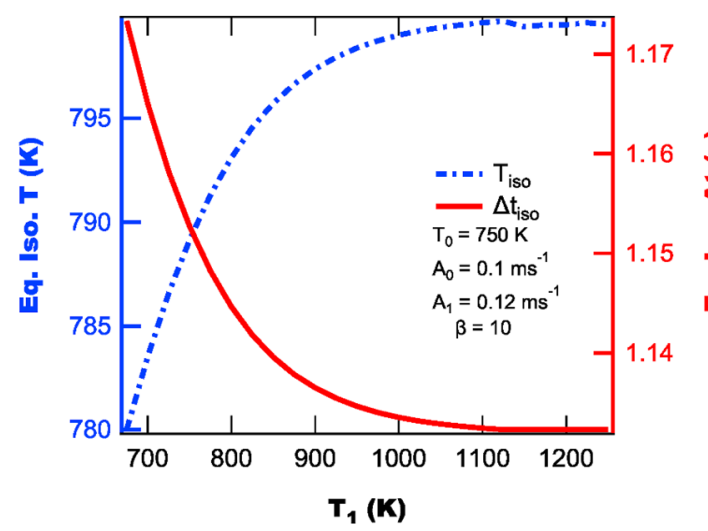

(e)

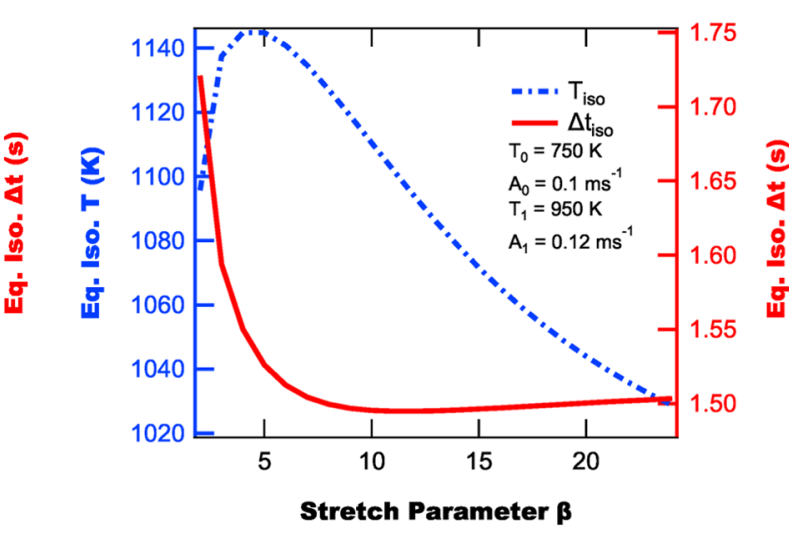

(b)

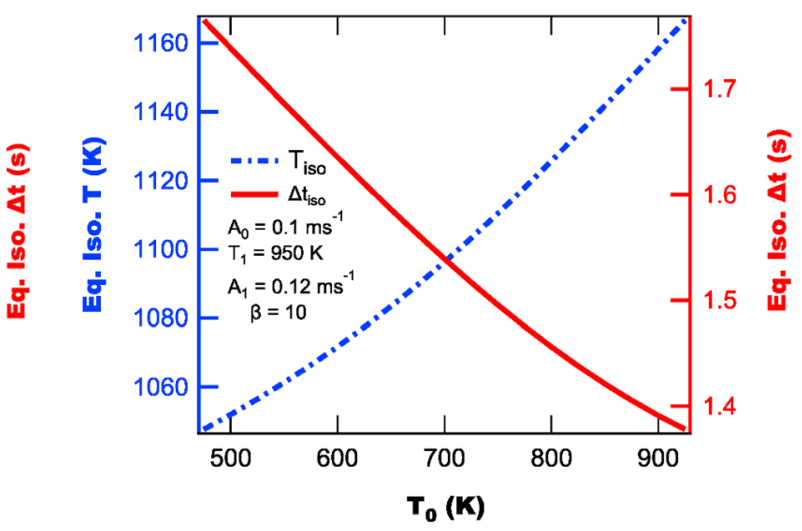

(d)

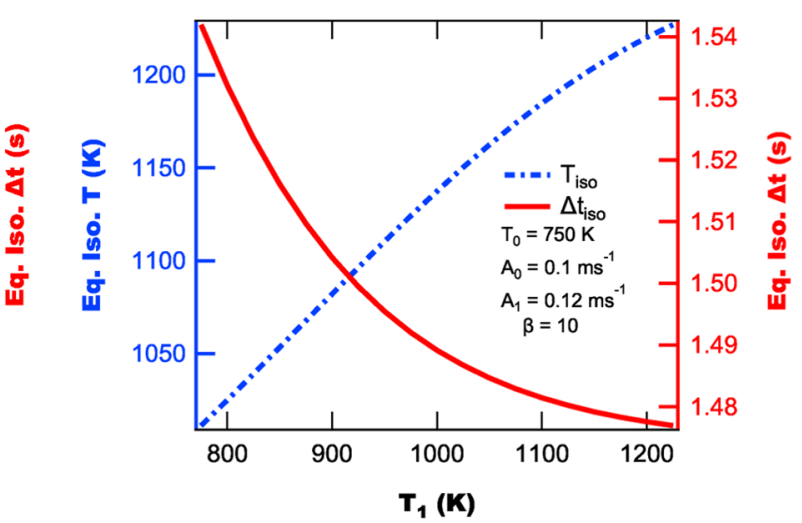

(f)

Fig. 9 Equivalent isothermal temperature and duration as a function of stretch parameter $\beta(\mathbf{a}, \mathbf{b}), T_{0}(\mathbf{c}, \mathbf{d})$, and $T_{1}(\mathbf{e}, \mathbf{f})$ for isothermal temperatures of $800 \mathrm{~K}(\mathbf{a}, \mathbf{c}, \mathbf{e})$ and $1273 \mathrm{~K}(\mathbf{b}, \mathbf{d}, \mathbf{f})$. Note that both

results depend on the parameters. With regard to the stretch parameter $\beta$, we observe that for the $800 \mathrm{~K}$ isotherm the equivalent isotherm's accuracy increases with increase in $\beta$, while for the $1273 \mathrm{~K}$ isotherm, the accuracy is found to peak near $\beta=4.5$ followed by a slow decrease in accuracy. This effect is found to be far more pronounced

the equivalent temperature and duration are found to be independent of the materials amplitude parameters

in the equivalent isothermal temperature than in the duration.

Turning to the materials' characteristic temperatures, we find that for both the $800 \mathrm{~K}$ and $1273 \mathrm{~K}$ isotherms the high-temperature material's characteristic temperature $\left(T_{1}\right)$ has a far greater impact on the temperature accuracy than the low-temperature material's characteristic 
temperature $\left(T_{0}\right)$, with increase in $T_{1}$ resulting in more accurate isothermal temperatures. On the other hand, the duration accuracy is found to be more sensitive to $T_{0}$, with the accuracy improving with increase in $T_{0}$. This dependence on $T_{0}$ is straightforwardly understood as the smaller $T_{0}$ is, the longer period of time the temperature ramp will be above $T_{0}$, which results in the equivalent duration being extended. As $T_{0}$ increases, the duration spent above it during temperature ramping decreases. This results in a more accurate determination of the isothermal duration.

These results demonstrate the general application of our model to TI sensors having different material parameters, with the qualitative results (underestimating $T_{\text {iso }}$ and overestimating $\Delta t$ ) being independent of the parameters, while the quantitative results differ significantly depending on the parameters. To apply the model to a specific TI sensor requires performing a full $\mathrm{TI}$ calibration to determine the sensor response as a function of temperature and duration. As many sensors' responses have the same functional form (Arrhenius temperature dependence and exponential duration dependence) as our model, it can be used to fit the sensor response to obtain the different material parameters. Once these are obtained, they can then be substituted into the model, as we just demonstrated for the general case.

\section{Conclusion}

In this study, we modeled the response of ex-situ thermal impulse sensors to non-isothermal temperature profiles using a phenomenological model developed for a TI sensor blend consisting of $p-E u: Z r_{2}$ and $p-D y: Y_{2} \mathrm{O}_{3}$. We considered the influence of four common non-isothermal temperature profile features on the TI sensors calculated equivalent isothermal temperature and duration. These common non-isothermal features include: a linear temperature ramp, exponential cooling, a temperature spike, and size-dependent heating.

We find that all four features result in the equivalent isothermal temperature being less than the peak temperature of the profile, meaning that the temperature determined by the $\mathrm{TI}$ sensors will always underestimate the actual temperature experienced by the sensors. In the case of the equivalent isothermal duration, we find that the effect of the different temperature features is feature dependent. For finite heating and cooling rates (surrounding an isotherm), we find that the measured duration is greater than the actual isothermal duration. However, in the case of a temperature peak during a lower-temperature isotherm we find that the measured duration is shorter than the total isothermal duration, but greater than the peak duration, with the measured duration approaching the peak duration as the peak temperature increases. Finally, we find that size-dependent heat transfer results in the calculated duration being less than the actual duration, with the error increasing with particle size.

These modeling results highlight the difficulties inherent to interpreting the TI measured by ex-situ TI sensors, with the measured equivalent isotherms always having lower temperatures and significantly different durations than the profiles they experienced. However, this modeling also sets up a framework for developing a more effective interpretation scheme that can take these various effects into account and produce more accurate $\mathrm{TI}$ measurements. For instance, we are currently developing a new calibration methodology that will correct for the in-lab calibrations heating and cooling rates in order to better determine the calibration parameters. Additionally, we are developing a method to modify the calibration curves to take into account the size distribution of our TI sensor particles. The combination of these two new methods should drastically improve the accuracy of our TI sensors.

Finally, while this modeling has focused on our specific implementation of ex-situ TI sensing, the same mechanism (e.g., irreversible phase transitions) underlies all ex-situ TI sensing techniques, meaning that these results will have wider applicability. These results can help to improve the accuracy of other ex-situ TI sensing techniques and provide the starting point for more technique-specific modeling of these effects. One possible avenue for future modeling is to compare different ex-situ techniques behavior under different non-isothermal temperature profiles and determine which techniques produce the most accurate results.

Acknowledgements We would like to thank Craig Watry for insightful discussions about modeling heat transfer into our sensor particles in explosive fireballs. This work was supported by the Defense Threat Reduction Agency, Award \# HDTRA 1-15-1-0044 and the National Institute of Justice, Award \#2015-DN-BX-K073 to Washington State University.

\section{Compliance with ethical standards}

Conflict of interest On behalf of all authors, the corresponding author states that there is no conflict of interest.

\section{References}

1. Gunawidjaja R, Myint T, Eilers $\mathrm{H}$ (2011) Stabilization of tetragonal phase in $\mathrm{ZrO}_{2}$ : Eu by rapid thermal heating. Chem Phys Lett 515:122-126

2. Myint T, Gunawidjaja R, Eilers H (2012) Spectroscopic properties of nanophase Eu-doped $\mathrm{ZrO}_{2}$ and its potential application 
for fast temperature sensing under extreme conditions. J Phys Chem C 116:21629-21634

3. Gunawidjaja R, Myint T, Eilers H (2011) Correlation of optical properties and temperature-induced irreversible phase transitions in Europium-doped yttrium carbonate nanoparticles. J Solid State Chem 184:3280-3288

4. Myint T, Gunawidjaja R, Eilers $\mathrm{H}$ (2012) Fast pyroprobe-heatinginduced structural changes of $\mathrm{Y}_{2} \mathrm{O}_{3}$ : Eu precursors and their optical signatures. J Phys Chem C 116:1687-1693

5. Gunawidjaja R, Myint T, Eilers $\mathrm{H}$ (2013) Temperature-dependent phase changes in multicolored $\mathrm{Er}_{x} \mathrm{Yb}_{y} \mathrm{Zr}_{1-x-y} \mathrm{O}_{2} / \mathrm{Eu}_{0.02} \mathrm{Y}_{1.98} \mathrm{O}_{3}$ core/shell nanoparticles. J Phys Chem C 117:14427-14434

6. Gunawidjaja R, Myint T, Eilers H (2014) Optical and morphological characterization of $\mathrm{Tb}_{0.01} \mathrm{Zr}_{0.99} \mathrm{O}_{2}$ /(precursor $\mathrm{Eu}_{0.02} \mathrm{Y}_{1.98} \mathrm{O}_{3}$ ) core/shell nanoparticles as temperature sensors in fast heating events. J Phys Chem C 118:5563-5569

7. Gunawidjaja R, Riega HD, Eilers H (2015) Irreversible phase transitions due to laser-based T-jump heating of precursor Eu: ZrO2/Tb: Y2O3 core/shell nanoparticles. J Solid State Chem 229:350-357

8. Anderson BR, Gunawidjaja R, Price P, Eilers H (2016) Spectroscopic changes of $\mathrm{Cr} 3+$ doped Al2O3. In: Frontiers in optics, vol 120, p 083102

9. Gunawidjaja R, Anderson BR, Eilers H (2018) Structural and spectroscopic characterization of irreversible phase changes in rapidly heated precursors of Europium-doped titania nanoparticles. J Solid State Chem 258:15-23

10. Anderson BR, Gunawidjaja R, Eilers H (2017) Spectroscopic signatures of sub-second laser-calcined $\mathrm{Dy}^{3+}$-doped oxide precursors for use in ex-situ thermal impulse sensors. J Phys Chem C 121:20955-20966

11. Anderson B, Gunawidjaja R, Eilers H. Chemically bonded ex-situ thermal impulse sensors for use in extreme environments. in preparation

12. Anderson BR, Gunawidjaja R, Price P, Eilers H (2016) Spectroscopic determination of thermal impulse in sub-second heating events using lanthanide-doped oxide precursors and phenomenological modeling. J Appl Phys 120:083102

13. Gunawidjaja R, Anderson B, y Riega HD, Eilers H (2017) Subsecond laser heating of thermal impulse sensors. AIP Conf Proc 1793:060014

14. Krewinkel R, Färber J, Lauer M, Frank D, Orth U, Gonzalez AY, Pilgrim C, Feist J, Saggese R, Berthier S, Araguas S (2016) Validation of surface temperature measurements on a combustor liner under full-load conditions using a novel thermal history paint. J Eng Gas Turbines Power 139:041508

15. Rabhiou AKA, Feist J (2011) Phosphorescent thermal history sensors. Sens Actuators A 169:18-26

16. Feist JP, Nicholls JR, Fraser MJ, Heyes AL (2006) Luminescent material compositions and structures incorporating the same

17. Feist JP, Karmakar Biswas S, Pilgrim CC, Sollazzo PY, Berthier S (2015) Off-line temperature profiling utilizing phosphorescent thermal history paints and coatings. J Turbomach 137:101003

18. Araguas Rodriguez $S$, Jelinek T, Michalek J, Yanez-Gonzalez A, Schulte F, Pilgrim C, Feist J, Skinner S (2018) Accelerated thermal profiling of gas turbine components using luminescent thermal history paints. J Glob Power Propuls Soc 2:344-361

19. Pilgrim C, Gonzalez, AY, Krewinkel RSR, Blaswich M, Feist J, Orth U, Rabs M, Frank D, Rodriguez SA (2017) Surface temperature measurements in an industrial gas turbine using thermal history paints. In: Proceedings of 12th European conference on turbomachinery fluid dynamics \& thermodynamics, pp ETC2017-303

20. Pilgrim CC, Heyes AL, Feist JP (2014) Thermal history sensors for non-destructive temperature measurements in harsh environments. AIP Conf Proc 1581:1609-1616
21. Bosze E, Hirata G, McKittrick J (2011) An analysis of $\mathrm{Y}_{2} \mathrm{O}_{3}: \mathrm{Eu}^{3+}$ thin films for thermographic phosphor applications. J Lumin 131:41-48

22. Pilgrim CC, Sollazzo PY, Berthier S, Feist JP, Biswas SK, Nicholls JR (2014) Thermal barrier sensor coatings - sensing damage and ageing in critical components. In: IET ISA 60th international instrumentation symposium, $\mathrm{pp}$ 1-8

23. Peng P, Su Z, Liu Z, Yu Q, Cheng Z, Bao J (2013) Nanowire thermometers. Nanoscale 5:9532-9535

24. Mah M, Manfred M, Kim S (2010) Measurement of rapid temperature profiles using thermoluminescent microparticles. IEEE Sens J 10:311-315

25. Mah M, Armstrong P, Kim S (2011) Thermal history sensing inside high explosive environments using thermoluminescent microparticles. In: IEEE Sensors, pp 1269-1272

26. Mah M, Armstrong P, Kim S (2013) Sensing the thermal history of high-explosive detonations using thermoluminescent microparticles. IEEE Sens J 13:1742-1747

27. Talghader J, Mah M (2012) Luminescent thermometry for sensing rapid thermal profiles in fires and explosions. In: Iniewski K (ed) Optical, acoustic, magnetic, and mechanical sensor technologies, CRC Press, Boca Raton, FL, pp 79-105

28. Talghader J, Mah M (2013) Sensing temperature inside explosions. In: Iniewski K (ed) Smart sensors for industrial applications, CRC Press, Boca Raton, FL, pp 259-272

29. Yukihara EG, Coleman AC, Bastani S, Gustafson T, Talghader JJ, Daniels A, Stamatis D, Lightstone JM, Milby C, Svingala FR (2015) Particle temperature measurements in closed chamber detonations using thermoluminescence from $\mathrm{Li}_{2} \mathrm{~B}_{4} \mathrm{O}_{7}: \mathrm{Ag}, \mathrm{Cu}, \mathrm{MgB}_{4} \mathrm{O}_{7}$ :Dy, Li and $\mathrm{CaSO}_{4}:$ Ce. Tb J Lumin 165:145-152

30. Yukihara EG, Coleman AC, Doull BA (2014) Passive temperature sensing using thermoluminescence: laboratory tests using $\mathrm{Li}_{2} \mathrm{~B}_{4} \mathrm{O}_{7}: \mathrm{Ag}, \mathrm{Cu}, \mathrm{MgB}_{4} \mathrm{O}_{7}: \mathrm{Dy}$, Li and $\mathrm{CaSO}_{4}: \mathrm{Ce}$, Tb. J Lumin 146:515-526

31. Doull BA, Oliveira LC, Wang DY, Milliken ED, Yukihara EG (2014) Thermoluminescent properties of lithium borate, magnesium borate and calcium sulfate developed for temperature sensing. J Lumin 146:408-417

32. Wang D, Doull BA, Oliveira LC, Yukihara EG (2013) Controlled synthesis of $\mathrm{Li}_{2} \mathrm{~B}_{4} \mathrm{O}_{7}$ : Cu for temperature sensing. RSC Adv 3:26127

33. Cornu L, Gaudon M, Jubera V (2013) $\mathrm{ZnAl}_{2} \mathrm{O}_{4}$ as a potential sensor: variation of luminescence with thermal history. J Mater Chem C 1:5419-5428

34. Lan $\mathrm{Y}$, Wang H, Skula N (2015) Determination of thermal history by photoluminescence of core-shelled quantum dots going through heating events. Part Part Syst Charact 32:65-71

35. Raffaelly-Veslin LLF, Champagnon B (2008) Thermal history and manufacturing processes of roman panes studied by raman spectroscopy. J Raman Spectrosc 39:1120-1124

36. TE Cherepanov VM, Chuev MA (1995) Structural instability and thermal history effects in oxygen-reduced superconducting ceramic $\mathrm{YBa}_{2}\left(\mathrm{Cu}_{0} .983-\mathrm{Fe}_{0.017}\right)_{3} \mathrm{O}_{6.8}$. Solid State Commun 93:921-926

37. Fair G, Kerans R, Parthasarathy $T$ (2008) Thermal history sensor based on glass-ceramics. Sens Actuators A 141:245-255

38. Mishra A, Wang J, Huang L (2014) Thermal sensitive quantum and phonon confinements for temperature mapping in extreme environments. J Phys Chem C 118:7222-7228

39. Mishra AK, Huang $L$ (2014) Substrate effect on phonon confinement in $\mathrm{TiO}_{2}$ nanoparticles for thermal sensing application. Appl Phys Lett 105:113104

40. Tollan CMPJ, Marcilla R (2009) Irreversible thermochromic behavior in gold and silver nanorod/polymeric ionic liquid nanocomposite films. ACS Appl Mater Interfaces 200:348-3529

41. Wacharasindhu SBJ, Montha S (2010) Tuning of thermochromic properties of polydiacetylene toward universal temperature 
sensing materials through amido hydrogen bonding. Macrmolecules 43:716-724

42. Sun H, Sun X, Yu M, Mishra AK, Huang L, Lian J (2014) Silica-gold core-shell nanosphere for ultrafast dynamic nanothermometer. Adv Funct Mater 24:2389-2395

43. Sun H, Yu M, Sun X (2013) Effective temperature sensing by irreversible morphology evolution of ultrathin gold island films. J Phys Chem C 117:3366-3373

44. Sun H, Yu M, Wang G, Sun X, Lian J (2012) Temperature-dependent morphology evolution and surface plasmon absorption of ultrathin gold island films. J Phys Chem C 116:9000-9008

45. Anderson BR, Gese N, Gunawidjaja R, Eilers H (2018) Nanoscale ex-situ thermal impulse sensors for structural fire forensics. Appl Spectrosc 72:1310-1321

46. Turmanova SC, Genieva SD, Dimitrova AS, Vlaev LT (2008) Nonisothermal degradation kinetics of filled with rise husk ash polypropene composites. Express Polym Lett 2:133-146

47. Chen $Y$, Wang $Q$ (2007) Thermal oxidative degradation kinetics of flame-retarded polypropylene with intumescent flame-retardant master batches in-situ prepared in twin-screw extruder. Polym Degrad Stab 92:280-291

48. Albano CL, Sciamanna R, Aquino T, Martinez JJ (2000) Methodology to evaluate thermogravimetric data using computational techniques in the polymer field. In: European congress on computational methods in applied sciences and engineering

49. Vlaev L, Markovska I, Lyubchev L (2003) Non-isothermal kinetics of pyrolysis of rice husk. Thermochim Acta 406:1-7

50. Roy PK, Surekha P, Rajagopal C, Choudhary V (2007) Thermal degradation studies of Idpe containing cobalt stearate as prooxidant. eXPRESS Polym Lett 1:208-216

51. Vlaev L, Georgieva V, Genieva S (2007) Products and kinetics of non-isothermal decomposition of vandium(IV) oxide compounds. J Therm Anal Calorim 88:805-812

52. Avramov I (2007) Kinetics of distribution of infections in networks. Physica A 379:615-620

53. Avrami M (1939) Kinetics of phase change. I general theory. J Chem Phys 7:1103-1112

54. Avrami M (1940) Kinetics of phase change, II transformationtime relations for random distribution of nuclei. J Chem Phys 8:212-224

55. Avrami M (1941) Granulation, phase change, and microstructure kinetics of phase change, III. J Chem Phys 9:177-184
56. Dickinson C, Heal G (1999) Solid-liquid diffusion controlled rate equations. Thermochim Acta 340-341:89-103

57. Ramis X, Cadenato A, Salla J, Morancho J, Valles A, Contat L, Ribes A (2004) Thermal degradation of polypropylene/starchbased materials with enhanced biodegradability. Polym Degrad Stab 86:483-491

58. Zhang F, Zhang J, Wang Y (2007) Modeling study on the combustion of intumescent fire-retardant polypropylene. eXPRESS Polym Lett 1:157-165

59. Incropera FP, DeWitt DP, Bergman TL, Lavine AS (2007) Fundamentals of heat and mass transfer, 6th edn. Wiley, New York

60. Anderson B, Gese N, Gunawidjaja R, Eilers H. Burn chamber demonstration of ex-situ thermal impulse sensors designed for use in structural fire forensics, submitted to Applied Spectroscopy

61. Watry C, Gunawidjaja R, Anderson B, Eilers H, Needham C, Peiris $S$ (2016) Micron-sized temperature sensor tests and calculations. In: 24th military aspects of blast and shock symposium, Canada, Halifax, pp 24-031

62. Anderson BR, Gunawidjaja R, Eilers H, Watry C, Peris S. Irreversible phase transitions in lanthanide-doped particles for temperature sensing applications under extreme conditions, in preparation

63. Biswas SK, Pilgrim CC, Sollazzo PY, Berthier S, Feist JP (2014) Thermal history paints - principles and progress. In: IET ISA 60th international instrumentation symposium 2014, pp 1-6

64. Amiel S, Copin E, Sentenac T, Lours P, Maoult YL (2018) On the thermal sensitivity and resolution of a YSZ: $\mathrm{Er}^{3+} / \mathrm{YSZ} \mathrm{Eu}^{3+}$ fluorescent thermal history sensor. Sens Actuators A 272:42-52

65. Rabhiou A, Kempf A, Heyes A (2013) Oxidation of divalent rare earth phosphors for thermal history sensing. Sens Actuators $B$ Chem 177:124-130

66. Gonzalez A, Ruiz-Trejo E, van Wachem B, Skinner S, Beyrau F, Heyes A (2015) A detailed characterization of $\mathrm{BaMgAl}_{10} \mathrm{O}_{17}$ : Eu phosphor as a thermal history sensor for harsh environments. Sens Actuators, A 234:339-345

Publisher's Note Springer Nature remains neutral with regard to jurisdictional claims in published maps and institutional affiliations. 